\title{
PECULIARITIES OF CONTACTLESS IGNITIONS OF ALTERNATING CURRENT ARC
}

\author{
N.M. MAKHLIN \\ SE Research Engineering Center of Welding and Control in Power Engineering \\ of E.O. Paton Electric Welding Institute, NASU \\ 11 Bozhenko Str., 03680, Kiev, Ukraine. E-mail: electro@paton.kiev.ua
}

\begin{abstract}
Considered are some important peculiarities of processes of contactless initial and repeated ignitions of alternating current arc in arc and plasma welding as well as electron voltage boosters. The latter generate the pulses of high and increased voltage being injected in inter-electrode gap for process realizing. It is shown that the most reasonable way for improvement of arc exciters and stabilizers is development of voltage boosters so called exciter-stabilizers. They differ by possibility to function in initial and repeated arc ignition modes, i.e. in the mode of stabilizing of alternating current arc burning. Optimized requirements on parameters of pulses generated by these devices are given based on multiple investigations, experience of development and application of voltage boosters. Some peculiarities of designing of combined arc exciter-stabilizers are considered. 32 Ref., 2 Tables.
\end{abstract}

Keywords: arc and plasma welding, alternating current, arc stability, glow and arc discharge, ignition voltage, electron arc exciter-stabilizers, energy, amplitude and duration of pulses

Advantages of alternating current (AC) welding, such as absence of magnetic blow, possibility of producing finer grain structure of weld metal and HAZ, simplicity, reliability and comparatively low price of welding power sources, provoked wide application of alternating current in manual coated-electrodes arc welding (MMA), in inert gases welding with non-consumable electrode (TIG) and other methods of arc and plasma welding. However, there are some disadvantages typical for AC welding. Low stability of arcing is the main. It is in particular characteristic for sine-wave welding current of industrial frequency. This is related with periodic arc extinctions due to de-ionization of inter-electrode gap, appearing at every change of arc current polarity. Therefore, researches on methods and means of increase of stability of AC welding arcs [1-9] have been carrying out for many decades.

Methods of increase of stability of burning of AC welding arcs can be conventionally divided on metallurgical and electrical.

Metallurgical methods are based on injection of elements with low ionization potential in the arc gap using electrode coating, welding wire, shielding medium and by other methods or via increase of thermionic current due to alloying of coated electrode rod or welding wire by elements with low electron work function [8, 10-13]. However, results of investigations and practice

(ㄷ) N.M. MAKHLIN, 2015 determined that possibility of increase of arcing process stability is limited by sufficiently narrow areas of welding modes.

Electrical methods of increase of AC arc stability in comparison with metallurgical ones are more available, varied and provide wider technological possibilities. Results of carried investigations $[5,6,8-10,14,15]$ showed that the following can be used for increase of $\mathrm{AC}$ arc stability:

- providing high rate of change of voltage and arc current in change of this current polarity;

- increase to 90-130 V of value of open-circuit voltage $U_{\text {op.cc }}$;

- using of free-burning pilot arc in TIG and plasma welding;

- application of pulse welding oscillators or generators of high-voltage pulses, amplitude value of output voltage of which makes from 3 to $10 \mathrm{kV}$ or generators of increased voltage pulses of $400-1000 \mathrm{~V}$ amplitude injected in the interelectrode gap at the moments corresponding to beginning of cathode formation on the part or at each change of welding current polarity.

Application of pulse voltage boosters [5, 6, $8-10,14-19]$ is the most widespread among the methods for increase AC arc stability due to low expenses and material consumption. There are number of developments and technical solutions. Nevertheless, problem of development of versatile solutions functioning in the mode of initial arc ignition as well as re-ignitions for arc burning stabilizing is still relevant.

Aim of the present work is study and generalisation of peculiarities of contactless initial ig- 
nition and re-ignitions of welding arc based on application of reference data and author's own experience and, taking into account peculiarities mentioned above, determination of requirements to high-voltage pulses and increased voltage pulses which should be generated by combined exciter-stabilizers.

Main peculiarities of initial arc ignition. The most widespread method for contactless initial $\mathrm{AC}$ arc ignition in the inter-electrode gap is its impact ionization by means of electric breakdown of this gap by high-voltage pulses.

There are Townsend and streamer-type breakdown mechanisms [3, 6, 8, 15, 20]. Breakdown of streamer-type takes place in the range of typical for arc and plasma welding values of $p d$ product (where $p$ is the gas pressure in the inter-electrode gap, and $d$ is the length of this gap). At that thin plasma channel, i.e. streamer, comes from anode to cathode. A streamer head has positive charge and intensifies field density close to the electrode at cathode approaching. This promotes for secondary electron emission. Due to this ohmic bridge is formed between electrodes of the gap, using which conduction electrons move from cathode to anode and provisions for appearance and development of spark discharge are created. The latter is a nonsteady discharge in gas, which is characterized by high temperature of plasma electrons in discharge channel and high level of gas ionization [6, 15, 20]. Formation of spark channel provides for step-wise increase of conductivity of the inter-electrode gap. Moreover, if welding source connected to this gap has sufficient power, electric spark can transform in stationary arc discharge with typical for it cathode and anode spots.

It is obvious that designing of the devices for initial arc ignition in arc and plasma welding requires taking into account the minimum necessary values of breakdown voltage of inter-elec-

Table 1. Approximation of values of breakdown voltage depending on gas content

\begin{tabular}{||l|c|c|}
\hline \multicolumn{1}{|c|}{ Gas content } & Breakdown voltage, V & $\begin{array}{c}\text { Length of gap between } \\
\text { welding electrodes, } \\
\text { mm }\end{array}$ \\
\hline Argon & $2400+150 d$ & $0.5-8.0$ \\
\hline \multirow{2}{*}{ Helium } & $3250+390 d$ & $0.5-8.0$ \\
\hline Nitrogen & $2940+920 d$ & $0.5-5.5$ \\
\cline { 2 - 4 } & $520+1360 d$ & $>5.5$ \\
\hline \multirow{2}{*}{ Carbon dioxide } & $3200+1200 d$ & $0.5-4.0$ \\
\cline { 2 - 4 } & $2400+1400 d$ & $>4.0$ \\
\hline \multirow{2}{*}{ Air } & $3050+1100 d$ & $0.5-4.5$ \\
\cline { 2 - 4 } & $1835+1370 d$ & $>4.5$ \\
\hline
\end{tabular}

trode gaps (ignition voltage of arc discharge). It should be noted that there is no rigid theory of arc discharge, explaining all complex of known factors [6, 8, 15, 20, 21]. In some important cases approximated theories $[6,15]$ can be used for description of mainly initial stage of arc discharge. One of which is based on Toepler hypothesis that conductivity of channel is proportional to charge passed though the gap, and the second grounds on Rompe and Weizel hypothesis. According to the latter all energy emitted in the channel is spent for increase of internal plasma energy and proportional to it channel conductivity.

Analytical calculation of values of breakdown voltage is significantly complicated since it requires experimental determination of values of several specific coefficients. For particular cases the results of work [15] can be considered as valid trial of analytical determination of breakdown voltage in the inter-electrode gaps in TIG or plasma welding. However, expressions given in [15] can be of minor applicability in engineer calculations. Practice of determination of necessary values of breakdown is based on data of experimental works, among which work [21] can be outlined. In it G.I. Leskov and V.P. Lugin made a conclusion that material of welding electrodes, composition of their coating and typical for welding rates of gas outflow do not effect breakdown voltage values under other things being equal. These researchers did not find any noticeable effect of pulse repetition rate (in the range from 100 to $3000 \mathrm{~Hz}$ ) and shape of highvoltage pulses being fed in the inter-electrode gap. It was determined that the main factors, determining value of breakdown voltage, are gas composition in the inter-electrode gap, its length and level of electric field inhomogeneity in the near-electrode areas. At that, the main molecular-kinetic gas characteristic, from which depends breakdown voltage, is section of electrons scattering on gas atoms and molecules.

The author based on results of works [21, 22] and own experiments has received the empiric expressions given in Table 1. They are used for determination of approximated averaged values of minimum necessary breakdown voltage in some gas media for technologically grounded gaps between welding electrodes and typical durations of high-voltage pulses.

Effect of breakdown pulse voltage on the inter-electrode gap provokes delay in charge formation [6, 15, 20], which mainly depends on concentration of gas particles in gap volume and exceed of applied pulse voltage in comparison with breakdown voltage in static field. This pre- 
determines the dependence (volt-second characteristic) of breakdown voltage on duration of pulse voltage, applied to the inter-electrode gap, at fixed breakdown possibility. If breakdown possibility makes $50 \%$ under conditions existing in plasma and arc welding, than volt-second characteristic can be represented as [6, 15]

$$
U_{\mathrm{br}}=\left(1+\sqrt[3]{\frac{a}{t_{\mathrm{p}} p d}}\right) U_{\mathrm{br.st}}
$$

where $a$ is the constant depending on type of gas in the inter-electrode gap; is the duration of voltage pulse applied to the inter-electrode gap; $U_{\text {br.st }}$ is the breakdown voltage in $t_{\mathrm{p}}$ uniform static field In real welding machines $t_{\mathrm{p}}$ usually does not exceed several milliseconds, and $U_{\text {br.st }}$ value can be determined using Cooper or Ritz data [20, 22].

If pulse voltage energy $W_{\mathrm{p}}$ applied to the inter-electrode gap is sufficient, than spark discharge takes place directly after gap breakdown, that, as was determined by B.Ya. Temkin [6, 15], is accompanied by significant rise of conductivity of the inter-electrode gap at its initial stage and its drop at final stage. Extinction of discharge or appearance of glow or arc discharge can take place at the end of spark discharge depending on conditions in the inter-electrode gap and characteristics of welding power source connected to it. The investigations showed that arc in the inter-electrode gap appears only when resistance of current conducting channel $R_{\mathrm{ch}}$ formed by spark discharge is less than some threshold value $R_{\mathrm{thr}}$. The latter depends on rate of power input from welding power source in the channel, voltage on gap $u(t)$ and other factors.

Values of pulse energy $W_{\mathrm{p}}$, providing arc ignition by spark discharge and received by us experimentally and approved by experience of application of voltage boosters, were recommended for different gas media and technologically grounded inter-electrode gaps. They make, J: $0.01-0.15$ for argon, $0.10-0.25$ for helium, $0.15-$ 0.40 for nitrogen, $0.30-0.50$ for carbon dioxide and for air.

Theory of AC arc ignition is not well developed. Alternating current of mainly industrial and close to it frequencies (from 50 to $200 \mathrm{~Hz}$ ) is used for arc and plasma welding, therefore, it can be assumed that $R_{\mathrm{ch}}<R_{\mathrm{thr}}$ condition is valid for the case of alternating current. Since arc discharge ignition mainly depends on voltage applied to the inter-electrode gap, than arc ignition pulse shall be injected in the inter-electrode gap close to $U_{\text {op.-c }}$ amplitude of arc power source. Multiple investigations found that start of generation of arc ignition pulse should make 75-
80 el. deg relatively to the moment corresponding to $U_{\text {op.-c }}$ value of arc supply source at sinewave of arc current. At that, condition of sufficiently high rate of increase of current of arc discharge should be fulfilled. Besides, conditions of emission from the electrodes are of high importance for performance of initial arc ignition. They can be very different for AC arc and depend on electrode material and on the fact whether the electrode is anode or cathode at the moment of arc ignition. This is in particular typical for TIG welding of aluminum and its alloys, in which arc ignition always takes place at time intervals when part being welded is the cathode.

Some peculiarities of re-ignitions of $\mathrm{AC}$ arc. Significant experience was accumulated as a result of multi-year extensive theoretical and experimental investigations generalized, for example, in [5, 6, 8-10, 23-25]. It allows explaining series of phenomena and peculiarities of $\mathrm{AC}$ arc as well as arc discharge stability.

Presence of pauses in arc discharge of the inter-electrode gap not far from current zero crossing value is typical peculiarity of $\mathrm{AC}$ welding arc. Temperature of gas in arc at the end of each current alternation before arc extinction and after it is significantly reduced and level of its ionizing, and, respectively, conductivity of gap considerably drops. At that, temperature of anode and cathode spots decline $[6,8,26]$. As a result of this after arc extinction at the end of previous alteration its repeated ignition in the beginning of the next period can take place at ignition voltage (peak) $U_{\mathrm{i}}$, value of which exceeds the value of arcing voltage $U_{\mathrm{a}}$. Analytical determination of $U_{\mathrm{i}}$ value is not possible up to the moment.

It was experimentally determined that $U_{\mathrm{i}}$ value is mainly determined by electrophysical properties of the electrodes and conditions in the inter-electrode gap. Besides, characteristics of processes in the inter-electrode gap, and, respectively, $U_{\mathrm{i}}$ values differ depending on electrode type. It was also determined that during the alternations, when welding electrode is the anode, $U_{\mathrm{i}}$ value in the most cases exceeds value of this voltage for alternations, in course of which the electrode is the cathode. The main factor determining $U_{\mathrm{i}}$ is the time of presence of residual plasma in the inter-electrode gap (time of plasma arc deionization $\left.t_{\text {deion }}\right)$ after arc discharge extinction not far from current zero crossing. It was experimentally proved that the lower potential of ionization of the inter-electrode gap and the higher $d t_{\mathrm{a}} / d t$ are, the longer $t_{\mathrm{deion}}$ and, respectively, lower $U_{\mathrm{i}}$ value will be. The same effect 
is achieved in the case of introduction of elements with low work function in the electrode composition. According to [10], $U_{\mathrm{i}}$ value makes 120 $165 \mathrm{~V}$ for electrodes of UONI-13/45 type at arc burning pauses not more than $2 \cdot 10^{-2} \mathrm{~s} . U_{\mathrm{i}}=40-$ $80 \mathrm{~V}$ for electrodes of OMM-5 and TsM-7 type containing easy-ionizing elements (potassium and sodium), and $U_{\mathrm{i}}>200-250 \mathrm{~V}$ for electrodes without coating at arc burning pauses not exceeding $1 \cdot 10^{-2} \mathrm{~s}$.

Peculiarities of processes taking place in the inter-electrode gap not far from current zero crossing in TIG welding become the most apparent in welding of parts from aluminum and its alloys. High values of $U_{\mathrm{i}}$ are typical for this case at transfer from straight polarity, when tungsten electrode is the cathode, to reversed one, at which part from aluminum or its alloy is the cathode, and $U_{\mathrm{i}}$ low value at transfer from reversed polarity to straight one. This phenomenon can have quality explanation by the fact that temperature of heated in pervious alternation non-consumable electrode does not have time for substantial changes at transfer from reversed polarity to straight one due to it low temperature conductivity and, thus, arc current appear even at very low values of voltage at the inter-electrode gap.

Transfer from straight polarity back to reversed one provides for the processes of another nature in the inter-electrode gap. Due to the fact that outer surface of the part from aluminum and its alloys being virtually always covered with oxide film, aluminum work function is rapidly reduced, and already at $60-80 \mathrm{~V}$ voltage at the inter-electrode gap provokes appearance of diffusion glow discharge. It is transferred in subnormal stage, and then in normal at further voltage recovery in the inter-electrode gap and rise of current through it. At that current rise takes place with constant voltage at normal stage of glow discharge.

This stage is also accompanied by cathode spraying that provokes local breaking of $\mathrm{Al}_{2} \mathrm{O}_{3}$ film and cleaning of weld pool from it. Further current growth through the inter-electrode gap promotes transfer of glow discharge in its abnormal stage. It is characterized by quick growth of voltage in the inter-electrode gap, achieving 220$240 \mathrm{~V}$ at $1 \mathrm{~A}$ current. Then, at further current growth, it is transferred in arc discharge with typical for it low burning voltage, which is 10-12 $\mathrm{V}$ more in comparison with values of arcing voltages at straight polarity alternations $[6,15,20]$.

Consideration of the peculiarities of processes taking place in the inter-electrode gap not far from current zero crossing in TIG welding shows that $U_{\mathrm{i}}$ value at change of polarity from straight to reversed one is determined by voltage peak in the inter-electrode gap at abnormal stage of glow discharge, proceeding to arc one. Taking this into account, $U_{\mathrm{i}}=240-250 \mathrm{~V}$ in the case of argon application as shielding gaps in TIG welding of parts from aluminum and its alloys, and $U_{\mathrm{i}}$ can make 300-350 V in the case of application of other gases in accordance with data given, for example, in [8, 20].

Since $U_{\text {op.-c }}$ of AC source should not exceed $80 \mathrm{~V}$ of effective value (113 V of amplitude value) according to the safety requirements in arc welding, than reliable repeated re-ignitions on practice can be provided only if easy-ionizing elements are present in the coating or electrode material. In all other cases stable arcing without taking special measures is impossible.

The most versatile and effective method for providing AC arc stability is short-time (pulse) increase of voltage in the inter-electrode gap at each change of polarity of current passing through this gap with the help of special devices. These devices are called arcing stabilizers and they represent itself increased voltage pulse generators, amplitude of which equals or exceed $U_{\mathrm{i}}$ value $[1,3,5,6,8,15-19,27]$. It was experimentally determined that duration of such pulses shall make $(0.05-0.10) \cdot 10^{-3} \mathrm{~s}$, and in separate cases $(0.2-1.0) \cdot 10^{-3} \mathrm{~s}$, for example, in consumable-electrode $\mathrm{CO}_{2}$ welding, depending on properties of welding power source and conditions in the inter-electrode gap. Energy $W_{\text {p.st }}$ of these pulses in all cases should provide transfer from abnormal glow discharge to arc one. Table 2 shows experimentally received by us and other researchers $[5,6,8,10] W_{\text {p.st }}$ values for pulses generated by arc burning stabilizers, which are recommended for different shielding media and technologically grounded inter-electrode gaps in welding of some metals and alloys.

Peculiarities of designing and ways of improvement of combined exciter-stabilizers. Structures of designing of special exciters and stabilizers of arcing are close between themselves, but these devices differ from each other by amplitude parameters of output pulses as well as algorithms and modes of work of their control assemblies.

Experience of application of arc exciters prove that all these devices fundamentally can provide effective stabilizing of burning process to the most AC welding arcs $[4,8,16,17,27]$. However, it requires significant enlargement of insulation of welding tool (for example, electrode 
Table 2. Value of pulse energy providing arc re-ignitions

\begin{tabular}{|c|c|c|c|}
\hline Material of part to be welded & Welding method & Gas composition or coating type & $W_{\text {p.st }}, \mathrm{J}$ \\
\hline \multirow[t]{5}{*}{ Low-carbon and alloyed steels } & \multirow[t]{2}{*}{ TIG } & Argon & $0.05-0.35$ \\
\hline & & Helium & $0.20-0.40$ \\
\hline & \multirow[t]{2}{*}{ MMA } & Lime fluorspar coating & $0.40-0.90$ \\
\hline & & Organic coating without iron powder & $0.20-0.35$ \\
\hline & MAG & Carbon dioxide & $0.60-1.20$ \\
\hline \multirow[t]{2}{*}{ Copper and copper-containing alloys } & \multirow[t]{6}{*}{ TIG } & Argon & $0.35-0.70$ \\
\hline & & Nitrogen & $0.50-1$ \\
\hline \multirow{2}{*}{$\begin{array}{l}\text { Non-ferrous metals and alloys } \\
\text { (except for cooper and aluminum) }\end{array}$} & & Argon & $0.25-0.50$ \\
\hline & & Helium & $0.35-0.65$ \\
\hline \multirow[t]{2}{*}{ Aluminum and its alloys } & & Argon & $0.45-0.90$ \\
\hline & & Helium & $0.50-1$ \\
\hline
\end{tabular}

holders for MMA) and welding circuit wires. More serious structural problems appear in the case of application of arc exciters for stabilizing the process of its burning in AC welding using MIG/MAG method. Besides, as shown above, energy of pulses necessary for arc burning stabilizing and injected in the inter-electrode gap exceeds energy necessary for initial arc ignition. Due to this, application of arc exciters for stabilizing of its burning requires to overstate the level of energy accumulated in the capacitive storages of generator of increased voltage pulses (GVP) of arc exciter. This provokes a necessity of increase of mass-dimension indices of these devices and their price.

Besides, application of arc exciters for stabilizing of $\mathrm{AC}$ arc burning demands complication of their control circuit due to differences of the moments of beginning of output pulse generation in exciters and stabilizers. For example, it was experimentally determined that pulse generated by arc exciter and injected in the inter-electrode gap at sine-wave welding current shall be generated at the moments corresponding to $75^{-}$ $80 \mathrm{el}$. deg phase relatively to zero wire moment of open-circuit voltage of arc power supply. At the same time, pulses stabilizing arc burning is good to be injected at the moments corresponding to $68-72$ el. deg phase $[4,6,8,10,15,27]$. It should be noted that application of arc exciters for stabilizing the process of its burning in TIG welding can promote accelerated erosion of nonconsumable electrode, thus providing rise of possibility of formation of defects in welded joint.

In order to provide arc re-ignitions the special burning stabilizers shall provide transfer from glow discharge in arc one via glow discharge abnormal stage at each shift of voltage polarity in the inter-electrode gap. For this the stabilizer pulses injected in the inter-electrode gap shall have sufficient energy and duration corresponding to peculiarities of arc re-ignitions as well as amplitude $U_{\text {st.p.m }}$, fulfilling $U_{\text {st.p.m }} \geq K_{c} U_{\text {ch }}$ condition, where $K_{c}=1.10-1.25$. As a rule, $U_{\text {st.p.m }}=$ $=400-600 \mathrm{~V}$, and in separate special models of arc burning stabilizers $U_{\text {st.p.m }}=700-950 \mathrm{~V}$.

The necessary condition for providing welding arc re-ignitions is correct selection of moment for injection of stabilizing pulse in the inter-electrode gap. For example, energy of pulse at it preliminary injection will be dissipated before appearance of glow discharge, due to what transfer of voltage via ignition peak will be virtually unrealizable.

Analysis of available reference data indicate that researchers do not have common opinion on a problem of selection of the moment of stabilizing pulse injection. It is an opinion of authors' of work [1] that the most appropriate moments for stabilizing pulse injection are the moments, when voltage in the inter-electrode gap after current zero crossing achieves $15-20 \mathrm{~V}$, and by opinion of author of work [28] it is 20-50 V value. The investigations, results of which are given in work [6], showed that stabilizing pulse shall be injected after formation of glow discharge in the inter-electrode gap, i.e. with some delay relatively to the moment of polarity change in the inter-electrode gap. Duration of this delay is determined by time of development of glow discharge, depends on current and rate of its change not far from zero values and on rate of voltage recovery in the inter-electrode gap. It makes from several microseconds to $200 \cdot 10^{-6} \mathrm{~s}$.

Delay of $(60-100) \cdot 10^{-6} \mathrm{~s}$ is usually achieved in arc stabilizers with the help of their control circuits. It provides for necessary delay of beginning of stabilizing pulse injection in the inter- 
electrode gap [4, 6, 10, 15 ] taking into account turning of switching key of stabilizer GVP. Repetition of stabilizing pulses injected in the interelectrode gap can equal the voltage frequency of supply mains or its double value, that is typical for most of arc burning stabilizers in MMA and TIG welding $[4,6,8,10]$.

One of the distinctive peculiarities of existing special arc burning stabilizers lies in the fact that output of their power circuit is as a rule connected directly to the inter-electrode gap, i.e. parallel to welding source output. The power circuit of such a stabilizer includes charging device, energy storage (mainly capacitive), current-limiting resistance or inductive element and discharge key (mainly thyristor). At that, capacitive storage can have parallel or series connection to charging device $[4,6,8]$.

Although such a connection of output of power circuit of the stabilizer is the simplest and cheapest one, however, it has significant disadvantage. Depending on nature, i.e. resistance or inductive, of current-limiting element, the discharge of stabilizer capacitive storage can be aperiodic or oscillating respectively. Electromagnetic processes, taking place in the circuit of discharge of stabilizer capacitive storage, are well studied and analyzed in series of works with the help of linear differential equations of the second order with non-zero initial conditions [5, 8, 29-31]. At that the assumptions were taken about full discharge (in each its cycle) of preliminary charged capacitive storage of stabilizer GVP and on invariance of conductivity of the inter-electrode gap during all discharge time. Analysis of solutions of known equations show that, first of all, discharge circuit Q-factor and current $i(t)$ in this circuit are proportional to conductivity of the inter-electrode gap. For the second, providing of necessary duration values of stabilizing pulse and amplitude of $i(t)$, making 60-100 A at capacitive storage charge voltage $U_{\mathrm{c} 0}=400-600 \mathrm{~V}$, requires that capacity of condensers of stabilizer capacitive storage shall be not less than several tens of microfarads. Parallel connection of stabilizer to the inter-electrode gap necessitates input or output transformer for galvanic separation with supply mains circuits [5, 8]. Besides, parallel connection of stabilizers significantly reduces its efficiency due to shunting effect of output impedance of welding power source or loss of higher frequencies (HF-filter) in a guard filter, preventing components of output circuits of welding source from effect of increased voltage pulses generated by stabilizer. Usually, HF-filter represents itself L inductance-capacitance section. It consists of se- ries arc high-frequency choke with coil calculated for passing of full arc current, and frequency condenser, which has parallel connection to welding power source output [6]. Significant disadvantage of parallel stabilizers with direct connection to the inter-electrode gap is fundamental impossibility of their application for contactless initial welding arc ignition.

Series arc exciters and stabilizers are more effective. They provide emission in the inter-electrode gap of almost all energy accumulated in forming circuits of their GVP (negligibly small part of this energy is dissipated in guard condenser, shunting output of welding source, and in welding circuit wires). Series connection of pulse voltage boosters in welding or auxiliary arc circuit has no need in HF-filter and application of guard condenser [6,15-17] is enough to prevent effect of pulses of high or increased voltage on welding or auxiliary power supply. Important advantage of series pulse voltage boosters is their characteristics from point of view of electromagnetic compatibility [16, 32].

Thus, consideration and analysis of indicated peculiarities of initial and repeated ignitions and special voltage boosters for realization of these processes show that development of combined exciter-stabilizers is possible under condition of series connection of these devices to arc circuit and improvement of circuit and design solutions of functional assemblies in their power circuit, in particular GVP, as well as algorithms of their control circuits.

\section{Conclusions}

1. Further theoretical and experimental investigations, in particular in the direction of nearelectrode phenomena, are necessary for more complete explanation of all collection of processes related with initial and repeated welding arc ignition, including $\mathrm{AC}$ arc.

2 . Results of consideration and generalization of peculiarities of contactless initial and repeated welding arc ignitions, received based on application of known reference data, theoretical and experimental works of different authors and own experience of development and use of means of these processes realizing, allowed determining the requirements for parameters of high-voltage pulses and pulses of increased voltage that shall be generated by combined exciter-stabilizers, as well as moments of beginning of injection of these pulses in the inter-electrode gap.

3. The main parameters of output high-voltage pulses generated by exciter-stabilizers shall have the following values in the mode of initial arc 
ignition depending on conditions in the interelectrode gap (its length, nature and gas pressure, shape and frequency of treatment of working tip of welding electrode and part to be welded), namely pulse energy from 0.01 to $0.50 \mathrm{~J}$, amplitude $3-10 \mathrm{kV}$, and duration (at the level of 0.05 of amplitude value) from 3 to $20 \mu$ s.

The values of main parameters of increased voltage pulses generated by exciter-stabilizers in the mode of AC arc stabilizing (at its re-ignitions) depending on degree of deionization and related with it reduction of conductivity of the interelectrode gap at each change of arc current polarity shall make from $0.2-1.0 \mathrm{~J}$ for pulse energy, from 400 to $950 \mathrm{~V}$ for amplitude, from 50 to $100 \mu$ s for duration (at the level of 0.05 of amplitude value), and in separate cases (for example, in consumable-electrode $\mathrm{CO}_{2}$ welding) from 0.2 to $1.0 \mu \mathrm{s}$.

4. Development of combined exciter-stabilizers is possible under condition that their designing provides for series connection of output circuits of these devices to welding or auxiliary arc circuit.

The author expresses his thanks to Engs A.G. Skirta and V.Yu. Buryak for valuable help in preparation of this work.

1. Paton, B.E., Zavadsky, V.A. (1956) Pulse arc ignition in gas-arc and manual arc welding. Avtomatich Svarka, 3, 26-35

2. Lauzhadis, A.I. (1967) Effect of current frequency on stability of arc and manual arc welding process. Ibid., 9, 29-32.

3. Leskov, G.I., Lugin, V.P. (1969) Alternating cur rent: Way to welding. Tula: Priok. Kn. Izd.

4. Troitsky, V.A. (1981) Method of smooth control of power sources containing longitudinal-capacitive compensation. Avtomatich. Svarka, 5, 8-12.

5. Dymenko, V.V. (1985) Increase in process stability and expansion of technological possibilities of alternating current consumable electrode welding: Syn. of Thesis for Cand. of Techn.-Sci. Degree. Kiev.

6. (1986) Equipment for arc welding: Refer. Book. Ed. by V.V. Smirnov. Leningrad: Energoatomizdat.

7. Pentegov, I.V., Dymenko, V.V., Rymar, S.V. (1995) Selection of open-circuit voltage in sources for alternating current manual arc welding. Avtomatich. Svarka, 5, 35-40.

8. Paton, B.E., Zaruba, I.I., Dymenko, V.V. et al. (2007) Welding sources with pulse stabilizing of arc burning. Kiev: Ekotekhnologiya.

9. Korotynsky, O.E. (2007) High-efficient power sources for arc welding based on inductance-capaci tive converters: Syn. of Thesis for Dr. of Techn. Sci. Degree. Kiev.

10. Leskov, G.I. (1970) Electric welding arc. Moscow: Mashinostroenie.
11. Morozkin, I.S. (2003) Control of welding arc ignition in mechanized modes of surfacing. Rostov-naDonu: RostGUPS.

12. Farson, D., Courardy, C., Talkington, J. et al. (1998) Arc initiation in gas metal arc welding. Welding Research Suppl., 8, 315-321.

13. Weinshenk, H.E., Schellhase, M. (1971) Wiederzundugscharakreristiken von Schweisslichtbogen mit abschmelzen der Elektrode. ZIS-Mitt., 13(12), 17061720 .

14. (1974) Technology of fusion electric arc welding of metals and alloys. Ed. by B.E. Paton. Moscow: Mashinostroenie.

15. Temkin, B.Ya. (1981) Theory and design of arc welding exciters: Syn. of Thesis for Cand. of Techn. Sci. Degree. Leningrad.

16. Dudko, D.A., Fedotenkov, V.G., Makhlin, N.M. (1980) Thyristor generators of current pulses of UPD-1 type. Avtomatich. Svarka, 6, 61-63.

17. Makhlin, N.M., Korotynsky, A.E. (2014) Analysis and procedure of calculation of series connection electronic devices for contactless arc excitation. The $\mathrm{Pa}^{-}$ ton Welding J., 1, 30-40.

18. Makhlin, N.M., Korotynsky, A.E. (2015) Asynchronous exciters and stabilizers of welding arc. Analysis and design procedure. Part 1. Ibid., 3/4, 24-35.

19. Makhlin, N.M., Korotynsky, A.E. (2015) Asynchronous exciters and stabilizers of arc. Analysis and calculation procedure. Part 2. Ibid., 7, 26-37.

20. Rajzer, Yu.P. (1987) Physics of gas discharge. Moscow: Nauka.

21. Leskov, G.I., Lugin, V.P. (1971) Investigation of electrical breakdown of gaps between welding electrodes. Svarochn. Proizvodstvo, 2, 10-11.

22. Mick, J., Kregs, J. (1960) Electrical breakdown in gases. Moscow: Inostr. Lit.

23. Paton, B.E., Lebedev, V.K. (1966) Electrical equipment for arc and slag welding. Moscow: Mashinostroenie.

24. Novikov, O.Ya. (1978) Stability of electric arc. Leningrad: Energiva.

25. Pokhodnya, I.K. (1967) Melting of electrode and interaction of metal with gases in arc welding: Syn. of Thesis for Dr. of Techn. Sci. Degree. Kiev.

26. Kirdo, I.V. (1956) About mechanism of re-ignition of welding arc. Avtomatich. Svarka, 6, 39-54.

27. Shmakov, E.I., Makhlin, N.M., Fedotenkov, V.G. et al. (1978) Application of alternating current for welding of low-alloy and alloy steels, aluminium and its alloys. Montazh. $i$ Spets. Raboty $v$ Stroitelstve, 4, 20-22.

28. Aldenhoff, B.J. Alternating current arc power source. Pat. 3328637 A1 USA. Int. Cl. B23K $9 / 06$. Publ. 27.06.1967.

29. (2008) Theoretical principles of electrical engineering: Refer. Book on theory of electric circuits. Ed. by Yu.A. Bychkov et al. St.-Petersburg: Piter.

30. Andrianov, A.A., Sidorets, V.N. (2009) Optimization of modes for stabilizing of alternating current welding arc. Elektrotekhnika $i$ Elektromekhanika, 2, 5-8.

31. Shcherba, A.A., Suprunovskaya, I.N. (2012) Principles of increase in rate of discharge currents rise in loading in limitation of their maximum values. Tekhnichna Elektrodynamika, 5, 3-9.

32. Makhlin, N.M., Fedotenkov, V.G., Livshits, D.M. et al. (1979) Suppression of radio interference generated by arc exciter of UPD-1 type. Avtomatich. Svarka, $12,55-57$

Received 13.05.2015 